Goulden, J. D. S. \& Sharpe, M. E. (1958). J. gen. Microbiol. 19, 76-86

\title{
The Infra-Red Absorption Spectra of Lactobacilli
}

\author{
By J. D. S. GOULDEN AND M. ELISABETH SHARPE \\ National Institute for Research in Dairying, University of Reading
}

\begin{abstract}
SUMMARY: The infra-red absorption spectra of 76 strains of lactobacilli representing 11 different species were examined. With only a few exceptions, the spectra could be grouped into 5 distinct spectral types, each corresponding to a Lactobacillus species or a group of related species. From a study of acetic acid extracts, it has been found possible to relate spectral differences to the relative concentrations of nucleic acids and carboxylate groups in the different organisms.
\end{abstract}

Since the original work of Stevenson \& Bolduan (1952) a number of reports have been published on the application of infra-red spectroscopy to the differentiation of bacteria and other micro-organisms. A paper by O'Connor, McCall \& Du Pré (1957) gives references to most of the relevant work published in the U.S.A., and to this should be added the papers by Thomas \& Greenstreet (1954), Lembke \& Kaufmann (1954), Greenstreet \& Norris (1957) and Rideal \& Adams (1957).

The classification of the lactobacilli is based on the work of Orla Jensen $(1919,1943)$ who defined three groups of lactobacilli which he further subdivided into a number of species, and also on that of Pederson (1938) who further defined the heterofermentative group. Much recent work has been done on the classification of these organisms; studies on the biochemical characteristics (Rogosa, Wiseman \& Mitchell, 1953; Briggs, 1953 $a$; Wheater, 1955 $a, b$; Davis 1955; de Man, 1956 $a, b$ ) and serological characteristics (Sharpe, 1955 $a$; Sharpe \& Wheater, 1957) have made possible the precise identification of many species of lactobacilli. Some of this work has now been confirmed by chromatographic analysis (Mattick, Cheeseman, Berridge \& Bottazzi, 1956; Cheeseman, Berridge, Mattick \& Bottazzi, 1957) and it was thought that the infra-red absorption spectra might provide useful information about the relationships between these organisms. The present work describes attempts to classify a number of species of Lactobacillus by this method, using representative strains from a collection of lactobacilli at this Institute; these have previously been examined here and identified by some or all of the techniques mentioned above.

For the purpose of studying species classification by spectroscopic methods, it was thought preferable to examine the spectra of whole organisms rather than the spectra of extracts as used by O'Connor et al. (1957). The method of sample preparation, which has been in use now for several years in our laboratory, consisted of incorporating the freeze-dried organisms in potassium bromide disks. The preparation of such disks has been described by Ford \& Wilkinson (1954) and has also been applied successfully to the study of bacteria by Rideal \& Adams (1957). 


\section{METHODS}

\section{Strains of lactobacilli}

The organisms used for this work consisted of 76 strains of lactobacilli from our collection, representing 11 different species. They included laboratory strains obtained from many different sources, and a number of fresh isolates from Cheddar cheese. The organisms examined were: 7 strains of Lactobacillus acidophilus, 6 of L. helveticus, 7 of L. bulgaricus, 6 of L. lactis, 2 of L. delbrueckii, 22 of $L$. casei (including 9 strains belonging to the serological group $\mathrm{C}$ of Sharpe \& Wheater, 1957; 10 strains of serological group B; 3 strains which gave the characteristic biochemical reactions of $L$. case $i$ but did not fall into any serological group), 2 strains of $L$. casei var. rhamnosus, 8 strains of $L$. plantarum, 6 of $L$. fermenti and 10 of $L$. brevis group. The $L$. brevis group comprised low-temperature heterofermentative lactobacilli falling into Briggs's (1953a) group VI; these could be further subdivided into 6 strains of $L$. brevis, 3 of L. buchneri and 1 of $L$. viridescens, a new species described by Niven \& Evans (1957).

Cultures were grown in a modification of Briggs's (1953 b) tomato juice medium consisting of: glucose 2\%; Evans's peptone 1.5\%; $\mathrm{NaCl} 0.5 \%$; Yeastrel $0.3 \%$; Tween $800.01 \%$ (all $\mathrm{w} / \mathrm{v}$ ); and tomato juice $10 \%(\mathrm{v} / \mathrm{v})$, the final $\mathrm{pH}$ value being 6.6. Strains of Lactobacillus acidophilus, $L$. bulgaricus, $L$. helveticus, L. lactis, L. delbrueckii and L. fermenti were incubated at $37^{\circ}$ for $24 \mathrm{hr}$.; and strains of L. casei, L. plantarum and L. brevis were incubated at $30^{\circ}$ for $48 \mathrm{hr}$. All organisms were subcultured at least three times in $10 \mathrm{ml}$. tomato juice medium before being examined. For preparing samples for spectroscopic studies, organisms were grown in $20 \mathrm{ml}$. tomato juice medium for the times specified above, centrifuged, and the organisms washed three times in sterile distilled water, the final washing taking place in the ampoules in which the organisms were to be freeze-dried. As lactobacilli are non-pathogenic, no attempt was made to kill the cultures before further treatment.

The washed organisms were then freeze-dried for about $6 \mathrm{hr}$. at a final vacuum of $0.01 \mathrm{~mm} . \mathrm{Hg}$ in an Edwards's LC 5 Freeze-drier, and no differences were observed in the spectra of the same cultures which had been dried for 3,6 or $12 \mathrm{hr}$. About $1 \mathrm{mg}$. samples of the freeze-dried powder were ground and mixed intimately with $200 \mathrm{mg}$. of dried potassium bromide (Analar) in a vibratory ball mill, and the material was then pressed under vacuum to provide optically clear disks $\frac{1}{2}$ in. in diameter. A second disk prepared from potassium bromide was placed in the comparison beam of the spectrophotometer. The instrument used was a Grubb Parsons S 3A double-beam spectrophotometer fitted with a sodium chloride prism, recording at a speed of $1 \mu / \mathrm{min}$. In all cases spectra were recorded over the 2-15 $\mu$ wavelength range, but since the $5-13 \mu$ region includes the bands of major interest, this limited region only is illustrated in the figures.

For this type of work, involving the observation of small changes in the shape and contour of absorption bands, it was found necessary to ensure that all specimens were examined under identical instrumental conditions. Duplicate 
spectra of many of the organisms were examined on different occasions, in order to check the reproducibility of the method. Owing to slight variable mechanical losses in the preparation of the sample disks, it was not possible to record duplicate spectra at exactly the same intensity, but in most cases the actual differences in transmission were only of the order of a few $\%$ and the different spectra could be compared directly on a roughly quantitative basis.

When organisms were not thoroughly washed, traces of tomato juice and other consituents of the medium remained on them (Sharpe, 1955 b). Under such conditions the freeze-dried samples were hygroscopic and in air were rapidly converted into sticky masses which were impossible to manipulate.

Liquid medium was used in preference to agar-solidified medium for growing the bacteria as it is much more convenient to use for lactobacilli and gave quite satisfactory results. To achieve maximum growth on agar plates, lactobacilli should be incubated under anaerobic conditions whereas in liquid medium this is not necessary.

Greenstreet \& Norris (1957) mentioned that the addition of carbohydrate to a medium may result in large changes in the spectra of bacteria. Since carbohydrate is necessary for the growth of lactobacilli, it must be added to media for growing them. As the present study is concerned only with the genus Lactobacillus, it was possible to use the same medium throughout, so that any effects due to the carbohydrate should be the same throughout.

\section{RESULTS}

\section{General characteristics}

From a detailed study of the spectra of the 76 strains so far examined, it has been found possible to group the spectra into 5 distinct types, each corresponding to a Lactobacillus species or group of related species. With a few exceptions, all the strains examined could readily be classified into the 5 types according to certain prominent features in their spectra. In the first instance, the spectra can be divided into 2 distinct types $X$ and $Y$. Type $X$ is characterized by a relatively strong band near $960 \mathrm{~cm} .^{-1}$ and by the presence of an intense band near $1230 \mathrm{~cm} .{ }^{-1}$. In most cases, the $1320 \mathrm{~cm} .^{-1}$ band is as strong as, or stronger than, the broad $1060 \mathrm{~cm} .^{-1}$ band. Broad weak bands are usually observed in the $910-770 \mathrm{~cm} .^{-1}$ region and strong shoulders are not usually observed on the higher frequency side of the $1060 \mathrm{~cm} .^{-1}$ band. Type $Y$ is characterized by the weakness or complete absence of the $960 \mathrm{~cm} .^{-1}$ band, coupled with the high intensity of the $1060 \mathrm{~cm} .^{-1}$ band compared with that of the $1230 \mathrm{~cm} .^{-1}$ band. The $910-770 \mathrm{~cm} .^{-1}$ region is usually free from weak bands and the $1060 \mathrm{~cm}^{-1}$ band usually carries a number of weak shoulders, particularly on the higher frequency side.

Within the $\mathrm{X}$ and $\mathrm{Y}$ spectral types, it is possible to subdivide the spectra further into two types $L$ or M. Most of the strains belonging to each species are of the same $\mathrm{L}$ or $\mathrm{M}$ type. Type $\mathrm{L}$ is characterized by the relatively low intensity of the $1400 \mathrm{~cm} \cdot .^{-1}$ band, as compared with the $1450 \mathrm{~cm} .^{-1}$ band. In 
addition to being broader in shape, the $1400 \mathrm{~cm} .^{-1}$ band is usually almost equal in intensity to the $1450 \mathrm{~cm} .^{-1}$ band. Type $M$ is characterized by a relatively strong $1400 \mathrm{~cm}^{-1}$ band compared with the $1450 \mathrm{~cm} .^{-1}$ band. The absorption in the trough between the $1650 \mathrm{~cm} .^{-1}$ and $1550 \mathrm{~cm} .^{-1}$ bands in the $M$ type is also greater than in the $L$ type.

A third feature is the weak band at $1725 \mathrm{~cm}^{-1}$ which is sometimes observed on the side of the strong $1650 \mathrm{~cm} .^{-1}$ band. This weak band is only discernible as a shoulder and is observed in the spectra of Lactobacillus plantarum and some of the $L$. brevis organisms. The strains classified according to these spectral features correspond to the various species and also to the larger groups of Orla Jensen (1919), as shown in Table 1.

\section{Table 1. Comparison of spectral types and Lactobacillus species}

\begin{tabular}{|c|c|c|c|}
\hline $\begin{array}{l}\text { Spectral } \\
\text { type }\end{array}$ & $\begin{array}{l}\text { Lactobacillus } \\
\text { species }\end{array}$ & $\begin{array}{l}\text { Orla Jensen } \\
\text { group }\end{array}$ & $\begin{array}{l}\text { General physiological } \\
\text { characters of group }\end{array}$ \\
\hline $\mathbf{X L}$ & $\begin{array}{l}\text { L. acidophilus } \\
\text { L. lactis } \\
\text { L. delbrueckii }\end{array}$ & \multirow{2}{*}{ Thermobacterium } & \multirow{2}{*}{$\begin{array}{l}\text { Homofermentative, usually grow- } \\
\text { ing at high temperatures and un- } \\
\text { able to grow at low temperatures }\end{array}$} \\
\hline $\mathbf{X M}$ & $\begin{array}{l}\text { L. bulgaricus } \\
\text { L. helveticus }\end{array}$ & & \\
\hline $\begin{array}{l}\text { YLa* } \\
\text { YLb† }\end{array}$ & $\left.\begin{array}{l}\text { L. plantarum } \\
\text { L. casei }\end{array}\right\}$ & Streptobacterium & $\begin{array}{l}\text { Homofermentative, growing at } \\
\text { low temperatures }\end{array}$ \\
\hline \multirow[t]{2}{*}{$\mathbf{Y M}$} & L. brevis group & Betabacterium & $\begin{array}{l}\text { Heterofermentative, growing at } \\
\text { low temperatures }\end{array}$ \\
\hline & L. fermenti & Betabacterium & $\begin{array}{l}\text { Heterofermentative, usually grow- } \\
\text { ing at high temperatures and un- } \\
\text { able to grow at low temperatures }\end{array}$ \\
\hline
\end{tabular}

Figures 1 and 2 show spectra of strains of each species. The spectra of the strains within each group will be discussed in detail below.

\section{Spectra of strains in each serological group}

Lactobacillus acidophilus. Spectral type XL, example A1, Fig. 1. Strains examined: A1, A3, A4, A12, A15, N4, BF3. The spectra of A3 and BF3 were atypical in that both spectra showed only a weak band at $960 \mathrm{~cm}^{-1}$, in addition to a relatively weak $1230 \mathrm{~cm} .^{-1}$ band. Such features are more characteristic of $Y$ spectral type organisms. However, both strains possessed the typical biochemical characteristics of $L$. acidophilus.

Lactobacillus lactis. Spectral type XL, example L3, Fig. 1. Strains examined: L 1, L3, L 4, L 18, L 19, AH 7. No exceptions were found in the spectra so far examined, and within this group it was most difficult to distinguish spectra of individual strains.

Lactobacillus delbrueckii. Spectral type XL, example D2, Fig. 1. Strains examined: D2, D10. Since only two strains were examined in this group, it would be improper to assign a definite spectral type for the whole group. Strains D2 and D10 appeared to show XL spectral-type features, although the $960 \mathrm{~cm} .^{-1}$ band in the spectrum of strain D10 was not very strong. 
Lactobacillus helveticus. Spectral type XM, example H21, Fig. 1. Strains examined: H 20, H 21, ME 10, MP 8, AH 4, PR 3. All the strains in this group showed $X$ type spectral features and although strains H20, H21, ME 10 and MP8 showed M type features, strains AH4 and PR3 showed an intermediate intensity for the $1400 \mathrm{~cm}^{-1}$ band and could not definitely be classified according to the $\mathrm{L}$ or $\mathrm{M}$ spectral types.

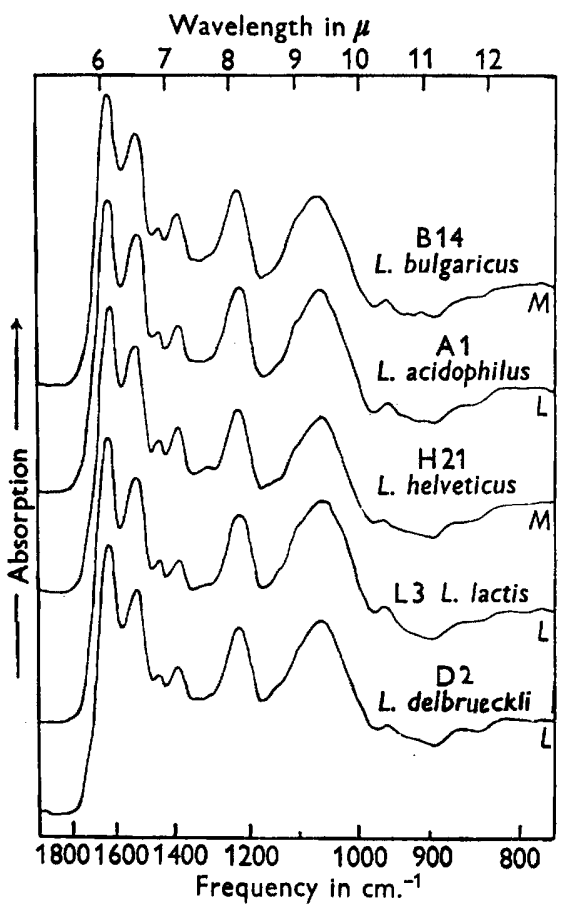

Fig. 1

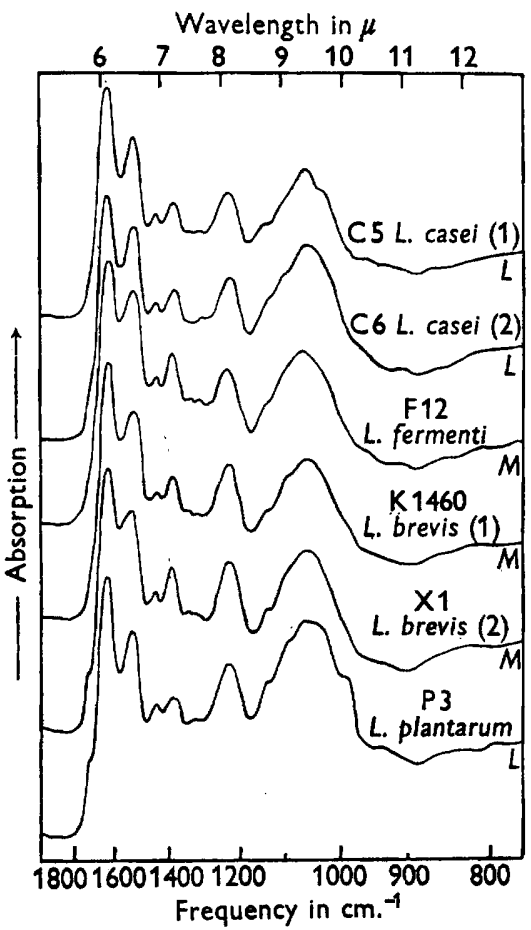

Fig. 2

Fig. 1. Spectra of type $X$ organisms. ( $L$ and $M$ indicate spectra of type $L$ or $M$.) Fig. 2. Spectra of type $Y$ organisms. ( $L$ and $M$ indicate spectra of type $L$ or $M$.)

Lactobacillus bulgaricus. Spectral type XM, example B 14, (Fig. 1), Strains examined: B2, B 12, B14, B15, B18, B21, B24. Within this species, all the strains gave spectra with pronounced $\mathbf{X}$ type characteristics. Most spectra were of the M type, but B 21 and B 24 showed L type features. Both of these strains gave the characteristic biochemical reactions of L. bulgaricus, but B 24 did not show the typical serological reactions of this species.

Lactobacillus casei. Spectral type YL, examples $\mathrm{C} 5$ and $\mathrm{C} 6$ (Fig. 2). All the strains within this group showed clearly $\mathbf{Y}$ type spectral features and, in addition, most spectra were of the $L$ type, although the $L$ features were not always very pronounced. The intensity of a shoulder near $1030 \mathrm{~cm} .^{-1}$ on the side of the $1060 \mathrm{~cm} .^{-1}$ band enabled the $L$. casei strains to be split into two subgroups, purely on the basis of their spectra. In subgroup 1 the $1030 \mathrm{~cm}^{-1}$ shoulder stood out against the general slope of the band, but in subgroup 2 , 
no shoulder was visible. The strains classified into the two subgroups according to their spectra were:

Subgroup 1 : A10, B163, B142, C2, C5, C10, C15, C18, CP3, H2, L16, CW 193, MR3A.

Subgroup 2: C6, C9, C24, P1, P9, P11, 07, A121, A 148, D3, SM4.

Those corresponded closely to the subdivision of the species Lactobacillus case $i$ into two serological groups (Sharpe, 1955 $a$; Sharpe \& Wheater, 1957), one group B, containing strains of $L$. casei and the other group $\mathrm{C}$, also containing strains of $L$. casei and, in addition, of $L$. casei var. rhamnosus. The biochemical characteristics of the $L$. casei strains in both serological groups were the same and strains could only be distinguished by serological tests. The strains falling into spectral subgroup 1 all belong to serological group $\mathrm{C}$, with the exception of $\mathrm{L} 16$ and CP3 which are serological group B, and the strains falling into spectral subgroup 2 all belong to serological group $B$, with the exception of strains P9, D3 and A 148. These last three have not yet been placed in serological group $B$, but they show serological relationships to other members of this group, which suggests that they are also members of it. This is confirmed by their spectra. P9 shows a weak band at $960 \mathrm{~cm} .^{-1}$, together with a strong $1230 \mathrm{~cm} .^{-1}$ band, these features being susggestive of an $\mathrm{X}$ type organism.

Within subgroup $1, \mathrm{H}_{2}$ and $\mathrm{C} 10$ could be differentiated from the other organisms within the subgroup by the presence of a weak shoulder near $1105 \mathrm{~cm}^{-1}$. These two were strains of $L$. casei var. rhamnosus, a variety which can be distinguished from $L$. casei biochemically (Rogosa et al. 1953) and also serologically by the possession of a particular type antigen (Orland, 1950; Sharpe, 1955a). Within subgroup 2, C6, P1, and P11 were all of the same serological type and could not be differentiated separately on the basis of their spectral features.

Lactobacillus plantarum. Spectral type YL, example P3, Fig. 2. Strains examined: P3, P5, P12, P14, AR 1, AB41, H268, SS140. The spectrum of H268 was completely different from that of any other lactobacillus so far examined in that the structure of the broad $1060 \mathrm{~cm} .^{-1}$ band was very complex. The spectra of both this strain and of P12 showed a strong band near $960 \mathrm{~cm}^{-1}$ similar to the $\mathrm{X}$ type organisms. $\mathrm{H} 268$ appears to be a characteristic strain of $L$. plantarum, but P12, however, is atypical biochemically, although it reacts with the plantarum group serum.

Apart from these two cases, all the spectra were of type $Y$ and, in addition, the shoulder near the $1725 \mathrm{~cm} .^{-1}$ was observed. This latter feature was found to be peculiar to all the $L$. plantarum spectra and to a few of the $L$. brevis spectra. Most of the strains in this group showed L type feature, but P 5, P12 and SS140 showed M type features.

Lactobacillus brevis group. Spectral type YM, examples K1460 and X1, (Fig. 2). Strains examined: K 1460, BC1, D210, V7, T3, T6, X1, X6, SL6, S 4i1 A. Apart from strain S41 A, which is not a typical $L$. brevis biochemically or serologically, and has recently been assigned to the new species $L$. viridescens (Niven \& Evans, 1957), all the spectra in this group showed both $\mathrm{Y}$ 
type and $M$ type characteristics. The intensity of the weak shoulder near $1725 \mathrm{~cm}^{-1}$ enabled most of the $L$. brevis spectra to be divided into two subgroups according to whether this band was absent (1) or weak (2). X6 showed the band of intermediate intensity, but the remaining strains could easily be subgrouped as follows :

\section{Type 1: K 1460, BC1, D210, V7, T3. \\ Type 2: X1, S41 A, T6, SL6.}

There appears to be no biochemical or serological evidence at present for such a further division of this group; the three strains of $L$. buchneri BC1, D210 and T3, all fall into type 1, but so do 2 strains of $L$. brevis.

Lactobacillus fermenti. Spectral type YM, example F12 (Fig. 2). Organisms examined: F1, F3, F4, F 12, F15, 010. All the strains in this group showed pronounced $Y$ type and $M$ type features in their spectra. In most cases, the $1400 \mathrm{~cm}^{-1}$ band was stronger than the $1230 \mathrm{~cm} \cdot .^{-1}$ band.

\section{Origin of bands in spectra}

The problem of accounting for the observed absorption bands in terms of molecular structure is particularly difficult, since in almost every case a number of different chemical entities give rise to absorption at the same frequency. Rideal \& Adams (1957) have been able to identify the components responsible for some of the bands by studying the spectra of various extracts from the whole organisms and the cell-wall material. The spectra of a number of the extracts used for the paper chromatographic technique (Mattick et al. 1956) have been examined in the course of this work and these have assisted in the interpretation of the spectra of the whole organisms.

Figure 3 shows the spectrum of the organism BC1 (L. brevis group) examined $(a)$ as whole organisms, and $(b)$ as the residue after extracting with $10 \%$ acetic acid at $37^{\circ}$ for $2 \mathrm{hr}$., followed by washing three times with water. Figure $3(c)$ shows the spectrum of the combined extracting and washing liquids, the water and acetic acid having been removed by warming in vacuo for several days. The spectra $(a)$ and $(b)$ were obtained from samples which had been freeze-dried and made up in potassium bromide disks. Spectrum (c) was obtained from a sample which had been cast as an aqueous film heat dried on a barium fluoride plate. Owing to absorption by the barium fluoride, the latter spectrum could only be examined up to about $13 \mu$.

The spectrum of whole organisms $(a)$ is of the type YM as shown by strains of the $L$. brevis group but the spectrum of the residue after extraction $(b)$ appears to have many characteristics of the $X$ and $L$ spectral types.

The ionized carboxyl group (- $\left.\mathrm{CO}_{2}^{-}\right)$is known to show a pair of absorption bands near 1600 and $1400 \mathrm{~cm}^{-1}$ (Bellamy, 1954). From an examination of the spectra of Fig. 3, it can be seen that the acetic acid treatment removes components absorbing at both these frequencies. Since amino acids absorb also near $1600 \mathrm{~cm}^{-1}$ (Bellamy, 1954) and these are known to be removed by the acetic acid treatment, a study of the $1400 \mathrm{~cm} .^{-1}$ band gives more precise in- 
formation about the carboxyl group. Methyl groups $\left(-\mathrm{CH}_{3}\right)$ absorb near 1400 and $1450 \mathrm{~cm}^{-1}$ (Bellamy, 1954), so that some of the loss of intensity of the $1400 \mathrm{~cm} .^{-1}$ band may well be due to the removal of smaller molecules (e.g. amino acids) containing a relatively large number of methyl groups. An examination of the exact frequencies of this band shows that it occurs at 1397,1380 and $1412 \mathrm{~cm} \cdot .^{-1}$ in $(a),(b)$ and $(c)$ respectively. Since the methyl group usually absorbs at frequencies slightly less than $1400 \mathrm{~cm} .^{-1}$ and the carboxyl group at slightly higher frequencies, it is considered that the main effect of the acetic acid extraction is to remove materials containing ionized carboxyl groups rather than methyl groups.

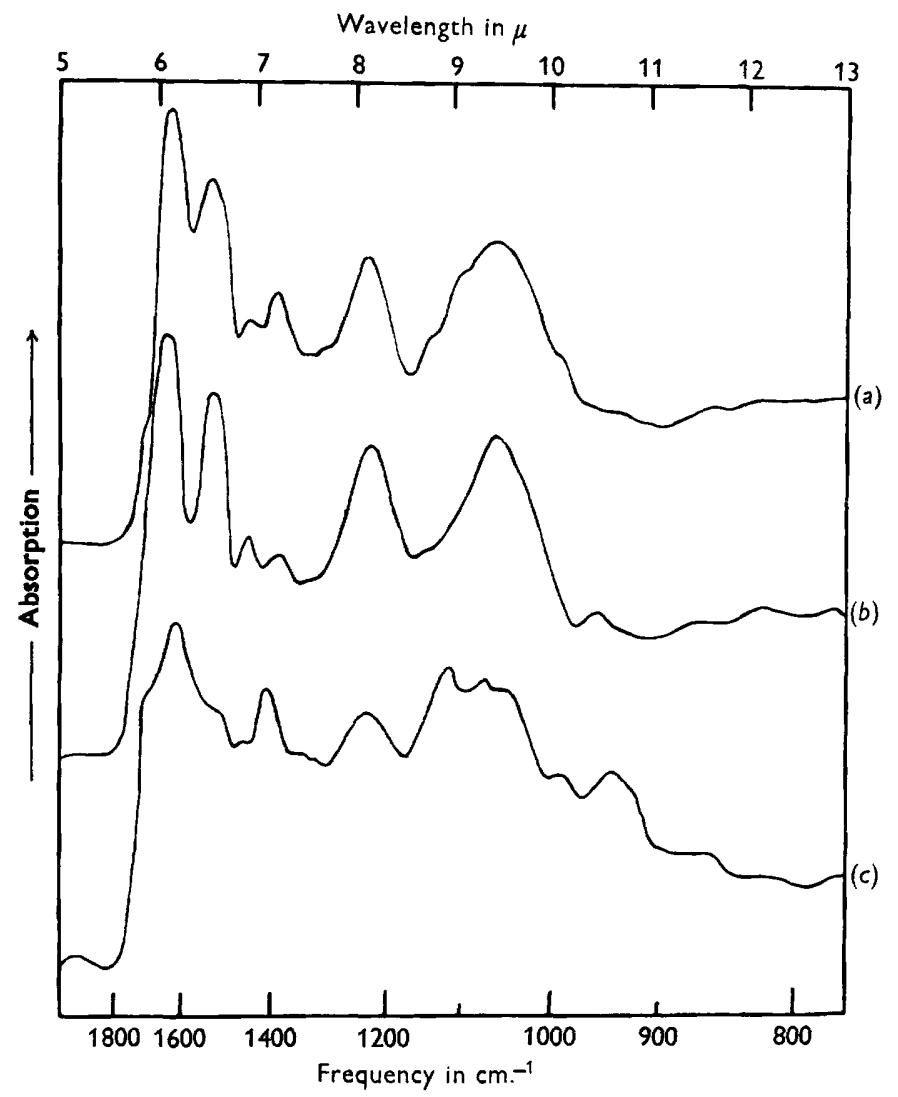

Fig. 3. Spectra of $\mathrm{BC} 1$ (L. breois group) and extracts: $(a)$ whole cells, (b) residue after acetic and acid extraction $(c)$ material extracted.

A study of the intensity of the $1400 \mathrm{~cm} .^{-1}$ band showed that this was most intense in the species Lactobacillus fermenti and L. brevis (subgroup 2), suggesting that such organisms contained a relatively high carboxylate ion concentration. It is of interest to note that paper chromatography of the acetic acid extracts of organisms in these groups showed particularly intense ninhydrin spots corresponding to the positions of glutamic and aspartic acids, i.e. acidic amino acids. 
A study of the shoulder near $1725 \mathrm{~cm} .^{-1}$ suggests that this band may be due to un-ionized carboxylic acid groups $\left(-\mathrm{CO}_{2} \mathrm{H}\right)$ or $\mathrm{O}$-acetyl groups rather than ester carboxyl groups occurring in fatty materials. This band is removed by acetic acid treatment and appears in the extracting solvent. Although this change is not very apparent in Fig. 3 , it was much more obvious in the spectra of T 6 (Lactobacillus brevis group) and its extracts. Repeated grinding of several strains with carbon tetrachloride failed to remove this band from the spectra.

Levine, Stevenson, Bordner \& Edwards (1955) have shown that the spectra of polysaccharides isolated from bacteria show very strong absorption near $1060 \mathrm{~cm} .^{-1}$, and also weaker absorption near $1230 \mathrm{~cm} . .^{-1}$, the former being associated with the hydroxyl groups. Sutherland \& Tsuboi (1957) have shown that nucleic acids also absorb in the same two regions of the spectrum, and their published spectra show that the relative intensities of the two bands are almost the same. In addition, the nucleic acid spectra show a band near $960 \mathrm{~cm} .^{-1}$ which does not appear in the spectra of the polysaccharides. This band can therefore be used as a measure of the nucleic acid content. Since it appears more intense in the X-type lactobacilli, it seems probable that such strains contain relatively more nucleic acid than the Y-type strains. Further confirmation is provided by the higher intensity of the $1230 \mathrm{~cm} \cdot .^{-1}$ band in the spectra of the X-type organisms.

Extraction with acetic acid leaves a residue with an apparently higher nucleic acid content (Fig. $3 b$ ). This change appears to be due to the removal of other constituents which absorb at 993 and $943 \mathrm{~cm} . .^{-1}$ on either side of the $960 \mathrm{~cm} .^{-1}$ band. The shape and intensity of the $1060 \mathrm{~cm} \cdot .^{-1}$ band in the spectrum of the extract (Fig. $3 c$ ) suggests that some polysaccharide material has also been extracted, whilst the $1725 \mathrm{~cm} \cdot .^{-1}$ band may be due partly to carboxylic acid or $O$-acetyl groups of the polysaccharide. It therefore seems likely that the extraction technique employed here removes both amino acids and polysaccharides, leaving a residue with increased nucleic acid content.

Greenstreet \& Norris (1957) have shown that the spectra of some aerobic spore-forming bacilli show very pronounced changes during the growth period. When a number of typical lactobacilli were examined at intervals during their growth period, only small changes were observed in the spectra. X-type strains appeared to show very little change, although during the early growth stages of some of the Y-type strains, the $960 \mathrm{~cm} .^{-1}$ band appeared almost as intense as in the spectra of the $\mathrm{X}$-type organisms. This presumably indicated a higher nucleic acid concentration during the early stages of growth.

In view of these observations, it might at first seem that the division of the organisms into $\mathrm{X}$ and $\mathrm{Y}$ types arises from differences in chemical composition brought about by using two different sets of growth conditions. In this work the organisms were usually grown under the conditions which ensured maximum growth. A selection of strains normally grown at $37^{\circ}$ for $24 \mathrm{hr}$. were however grown at $30^{\circ}$ for $48 \mathrm{hr}$. and vice versa. As expected, slight changes in spectra were observed, but only in a few cases did the different growth conditions cause changes large enough to change the $\mathbf{X}$ or $\mathbf{Y}$ character of the spectrum. In none of the cases examined was it possible to change the $\mathrm{L}$ or 
$\mathbf{M}$ character of the spectrum. Further evidence in this matter is provided by the Lactobacillus fermenti and $L$. brevis strains, which all gave rise to YM type spectra, although grown for $24 \mathrm{hr}$. at $37^{\circ}$ and $48 \mathrm{hr}$. at $30^{\circ}$ respectively.

\section{DISCUSSION}

The classification of lactobacilli according to spectral type corresponds in many respects to other methods of classification. Orla Jensen's (1919) broad division of the lactobacilli into Thermobacteria, Streptobacteria and Betabacteria, which was based on their physiological and nutritive characteristics, confirms some of our groupings; strains possessing the $\mathrm{X}$ type of spectra fall into the Thermobacteria, whilst strains possessing the $\mathrm{Y}$ type fall into the Streptobacteria or the Betabacteria. This division is also associated with the manganese requirements of the organisms. It was observed by Orla Jensen (1943) and later confirmed by cne of us (M.E.S.) that, whilst the Thermobacteria require only traces of mangane.ie for optimum growth, the Streptobacteria and Betabacteria require relatively large amounts. Further subdivision of the $\mathbf{X}$ and $\mathbf{Y}$ groups into the $L$ and $M$ types by their spectra also corresponds to other methods of classification. The $\mathrm{X}$ group-the Thermobacteria-are divided into the XL type containing Lactobacillus acidophilus and L. lactis, which are similar biochemically, and also the less closely related $L$. delbrueckii, and the XM type containing $L$.bulgaricus and $L$. helveticus, which both belong to the same serological group and also possess very similar biochemical characteristics. The $\mathbf{Y}$ group also shows further subdivisions, corresponding to the Streptobacteria (type YL) which are further divided into species $L$. casei and $L$. plantarum, and the Betabacteria (type YM) which are not further divided into species.

From this study of the spectra of the lactobacilli and their extracts, it would seem that organisms with the $\mathbf{X}$-type spectra contain relatively larger amounts of nucleic acid than those of the $\mathbf{Y}$ type. The M-type organisms appear to contain relatively larger amounts of ionized carboxylate groups than the $\mathbf{L}$ type organisms, although the evidence is insufficient to decide whether such groups are due largely to the polysaccharide or amino acid components.

Thus it can be seen that the classification of lactobacilli according to their infra-red spectra is related to changes in the chemical composition of the organisms and is in agreement with the differentiation of species by other methods.

We wish to thank Dr A. T. R. Mattick who originated this work, Dr G. W. Scott Blair for helpful advice and encouragement, Dr G. C. Cheeseman for most useful discussions and for kindly preparing the acetic acid extracts for this work; and Miss E. J. Adams and Miss J. Kingston for technical assistance.

\section{REFERENCES}

Bellamy, L. J. (1954). Infra-red Spectra of Complex Molecules. London: Methuen. Briggs, M. $(1953 a)$. The classification of lactobacilli by means of physiological tests. J. gen. Microbiol. 9, 234.

Briggs, M. (1953b). An improved medium for lactobacilli. J. Dairy Res. 20, 36.

Cheeseman, G. C., Berridge, N. J., Mattick, A. T. R. \& Bottazzi, V. (1957). The differentiation of bacterial species by paper chromatography. III. An examination of the Lactobacillus casei-plantarum group. J. appl. Bact. 20, 195. 
O'Connor, R. T., McCall, E. R. \& Du PrÉ, E. F. (1957). Differentiation of microorganisms by means of the infra-red spectra of their acetone extracts. J. Bact. $73,303$.

Davis, G. H. G. (1955). The classification of lactobacilli from the human mouth. J. gen. Microbiol. 13, 481 .

Ford, M.A.\& WiLkinson, G. R. (1954). The preparation and properties of alkali halide disks with special reference to their use in spectroscopy. J.Sci. Instrum. 31, 338.

Greenstreet, J. E. S. \& Norris, K. P. (1957). The existence of differences between the infra-red absorption spectra of bacteria. Spectrochim. Acta, 9, 177.

LembKe, A. \& KaUfmanN, W. (1954). Spektralphotometrische Messungen an Bakterien im ultraroten Bereich. Kiel. Milchw. forsch. 6, 619.

Levine, S., Stevenson, H. J. R., Bordner, R. H. \& Edwards, P. R. (1955). Typing of Klebsiella by infra-red spectrophotometry. J. infect. Dis. 96, 193.

MaN, J. C. DE (1956 $a)$. De eigenschappen van enige stammen van bacterien behorende tot het geslacht 'Thermobacterium' Orla-Jensen. Ned. melk- en Zuiveltijdschr. 10, 190.

MAN, J. C. DE (1956b). Enige eigenschappen van staafvormige melkzuurbacterien, geisoleerd uit Nederlandse Kaas. Ned. melk- en Zuiveltijdschr. 10, 240.

Mattick, A. T. R., Cheeseman, G. C., Berridge, N. J. \& Bottazzi, V. (1956). The differentiation of species of lactobacilli and streptococci by means of paper partition chromatography. J. appl. Bact. 19, 310.

Niven, C. F. \& Evans, J. B. (1957). Lactobacillus viridescens Nov. Spec., a heterofermentative species that produces a green discolouration of cured meat pigments. J. Bact. 73, 758.

Orla Jensen, S. (1919). The Lactic Acid Bacteria. Copenhagen: Andr. Fred. Host and Son.

Orla Jensen, S. (1943). The Lactic Acid Bacteria, 3rd ed. Copenhagen: Einer Munksgaard.

Orland, F. J. (1950). A correlation of antigenic characteristics among certain bacteria of the Lactobacillus group. J. infect. Dis. 86, 63.

Pederson, C. S. (1938). The gas-producing species of the genus Lactobacillus. $J$. Bact. 35, 95.

Rideal, E. K. \& Adams, D. M. (1957). The interpretation and use of bacterial infrared spectra. Chem. \& Ind. p. 762.

Rogosa, M., Wrseman, R. F., Mitchell, J. A., Disraely, M. N. \& Beaman, A. J. (1953). Species differentiation of oral lactobacilli from man including descriptions of Lactobacillus salivarius Nov. Spec. and Lactobacillus cellobiosus Nov. Spec. J. Bact. 65. 681,

Sharpe, M. E. (1955a). A serological classification of lactobacilli. J. gen. Microbiol. $12,107$.

Sharpe, M. E. $(1955 b)$. Haptene substances in culture media for lactobacilli. J. gen . Microbiol. 13, 198.

Sharpe, M. E. \& Wheater, D. M. (1957). Lactobacillus helveticus. J. gen. Microbiol. $16,676$.

Stevenson, H. J. R. \& Bolduan, O. E. A. (1952). Infra-red spectrophotometry as a means for identification of bacteria. Science, 116, 111.

Sutherland, G. B. B. M. \& Tsuboi, M. (1957). The infra-red spectrum and molecular configuration of sodium deoxyribonucleate. Proc. Roy Soc. 239 A, 446.

Thomas, L. C. \& Greenstreet, J. E. S. (1954). The identification of micro-organisms by infra-red spectrophotometry. Spectrochim. Acta, 6, 302.

WheATER, D. M. $(1955 a)$. The characteristics of Lactobacillus acidophilus and $\boldsymbol{L}$. bulgaricus. J. gen. Microbiol. 12, 123.

Wheater, D. M. $(1955 b)$. The characteristics of Lactobacillus plantarum, L. helveticus and L. casei. J. gen. Microbiol. 12, 133. 